\title{
Implementation of energy efficiency programs using cogeneration based on internal combustion engines
}

\author{
Eduard MINCIUC \\ University Politehnica of Bucharest, Bucharest, Romania \\ eduard.minciuc@energ.pub.ro \\ Roxana PĂTRAŞCU \\ University Politehnica of Bucharest, Bucharest, Romania \\ George DARIE \\ University Politehnica of Bucharest, Bucharest, Romania \\ Ioana DIACONESCU \\ University “Dunărea de Jos" of Galaţi, Galati, Romania
}

\begin{abstract}
The paper presents an analysis of implementation of CHP plants based on internal combustion engines at different industrial companies. The authors have presented general aspects regarding utilization of internal combustion engines for cogeneration. There have been presented different possibilities of classification of internal combustion engines. Further on authors have presented different possibilities for increasing the efficiency of internal combustion engines, including: supercharging compression ratio increase, advanced heat recuperation for combined production of heat and power. There have also been presented different measures for increasing energy efficiency on site, including measures for CHP plant and internal combustion engines and measures for other auxiliary equipment and measures for technological equipment. In the second part of the paper authors have presented three case studies of utilization of internal combustion engines at a cogeneration plant for different industrial companies: cogeneration plant at a company from pharmaceutical sector, cogeneration plant at a beer production company and cogeneration plant at a company of electrical insulation materials. The results of the analysis led to following conclusions: implementation of cogeneration solutions based on internal combustion engines lead to significant financial savings, implementation of cogeneration solutions based on internal combustion engines can also lead to reducing environmental impact, it ensures higher global energy production efficiency and higher power efficiency compared to National Power System and to separate power and heat generation, it can lead to increased safety in energy supply of the company, it can also increase the reliability of power supply in cases of National Power Grid faults.
\end{abstract}

Keywords: CHP, energy efficiency, internal combustion engine, energy efficiency program.

\section{Introduction}

Internal combustion engines are used in cogeneration for production of electricity and heat based on utilization of fossil fuels, usually natural gas or other liquid fuel. The heat production is based on heat recovery from engine's cooling systems and from flue gases of the engine, (Athanasovici et al., 2010).

The available heat is used through heat exchangers for different technological processes, thus leading to higher energy efficiency of combined heat and power compared to separate energy production of the same amount of electricity and heat. In some cases, when technological process need apart from power and heat also cold, the heat available 
from internal combustion engine can be used in a absorption cooling machine to generate cold; this process is known as trigeneration of electricity, heat and cold. It also leads to higher energy efficiency, as cogeneration, compared to separate production of those three forms of energy.

The main criteria taking into consideration for classification of internal combustion engines are the following:

PICBE $\mid 210$

- $\quad$ Combustion ignition process.

- Thermodynamic cycle duration.

- $\quad$ Process of formation of air-fuel mixture.

- $\quad$ Number of piston movements per cycle.

- $\quad$ Aggregation state of used fuel.

- Number of fuels used.

- Number of cylinders.

The internal combustion engines can also be classified based on the thermodynamic cycle, as follows:

1. Spark ignition engine (Otto cycle).

2. Compression ignition engine (Diesel cycle).

3. Fuel jet ignition engine (Sabathe cycle) and dual fuel engine (Diesel-Gas).

Increasing the power that can be delivered by an engine can be done through installation of a turbo-blower with high variable speed, which uses flue gases exiting the engine as a drive force.

For the same power, due to supercharging the volume of the engine decreases compared to a standard one with about 23 to $29 \%$. All engines used for cogeneration of heat and power are supercharged due to all advantages that this technology brings.

Spark ignition engines can operate using two types of fuel: liquid or gaseous.

Internal combustion engines operating using gaseous fuel are called gas internal combustion engines. As primary energy source there can be used natural gas, coke gas, probe gas, biogas, etc.

Internal combustion engine using gaseous fuels can be divided into two categories:

1. Gas internal combustion engines using rich fuel mixture (standard engines), having excess air between 1.2 and 1.3 .

2. Gas internal combustion engines using lean fuel mixture (so called lean burn engines), having excess air of 1.5 and higher.

Compression ignition engines differ from those with spark ignition due to the fact that there is no need to have carburetor and the igniter.

Diesel engines can be divided into two main groups:

- $\quad$ Slow diesel engines.

- $\quad$ Fast diesel engines.

This technology used in cogeneration mode can lead to different advantages. Cogeneration can be defined as combined and simultaneous production of heat and power using the same primary energy source and the same equipment.

Compared to separate energy production cogeneration can lead to following advantages (Athanasovici et al., 2010, Patrascu and Minciuc, 2013a, Patrascu et al., 2013, Patrascu et al., 2011):

- Higher global energy efficiency compared to separate production of heat and power. 
- Lower fuel consumption compared to separate production, thus achieving fuel savings, which can be 10-20\% depending on the case.

- Due to fuel savings there is a reduction of green house gases emissions, thus reducing environmental impact (Patrascu et al., 2009).

- Due to concentration of power and heat production at the same energy generating facility there can be obtained lower power and heat production costs, which can lead to lower energy prices.

- Increased reliability and safety of energy supply of industrial companies, especially when the CHP plant is based on site.

\section{Energy efficiency measures based on cogeneration using internal combustion engines}

Implementation of measures for increasing energy efficiency using cogeneration based on internal combustion engines assumes the following (Patrascu and Minciuc, 2013b):

- Increasing performance criteria of all used equipment (internal combustion engines, heat exchangers and energy transport and distribution systems).

- $\quad$ Correct sizing and choosing of energy equipment.

- $\quad$ High annual duration of simultaneous use of power and heat.

Bellow there are presented different solutions for increasing energy efficiency of an internal combustion engine.

Supercharging is practically the increase of air flow or of air-fuel mixture (depending on the used thermodynamic cycle) leading to increasing the initial pressure.

Increasing the initial pressure, which can be achieved through using different types of air compressors, can ensure a total supercharging during the entire phase of admission, or partial supercharging during a part of the admission phase. Using this method, the thermodynamic efficiency of internal combustion engine increases, which leads to increasing of power efficiency that can reach values of $42-44 \%$.

There are different methods of supercharging, but the most used ones are the following:

- Mechanical supercharging, when compressor is directly mechanically driven by the engine. This solution is applicable to engines with supercharging pressure that does not exceed 1.5-1.6 bars.

- Turbo-supercharging, which uses residual energy of flue gases exhausted from the engine. The value of supercharging pressure in this case is between 1.5 and 4 bars. In this case compressor is driven by a mini-turbine that is driven by exhaust gases evacuated from the engine. Due to high rotation speed of the mini-turbine (up to $60000 \mathrm{rpm}$ ) the energy efficiency is also quite high ensuring supercharging of the engine at different loads, including partial ones.

Another method of increasing energy efficiency of the thermodynamic cycle of internal combustion engine is to increase the compression ratio of the engine. This is more a technological issue and implies different methods of construction of the engine.

The increase of power capacity of the engine is done by increasing the capacity of cylinders and increasing the number of cylinders. 
Another method to increase, at this time, the global energy efficiency of internal combustion engines is through advanced recuperation of residual heat from the engine's cooling systems and from flue gases.

Thus, the engines that recover entire heat and generate hot water $\left(90-95{ }^{\circ} \mathrm{C}\right)$ can reach global energy efficiencies of about 85-87 \%, and this is also due to the fact that flue gases are cooled down to $100-120{ }^{\circ} \mathrm{C}$ (with about $10-20{ }^{\circ} \mathrm{C}$ upper dew point corresponding to partial pressure of water vapor from flue gases). This also leads to reduction of thermal pollution and the environment.

In case of separate production of hot water using heat from engine's cooling systems (in this case hot water temperature can reach up to $70-75^{\circ} \mathrm{C}$ ), and heat from flue gases is used for steam generation, flue gasses temperature evacuated into atmosphere increases (up to $150-180^{\circ} \mathrm{C}$, depending on the generated steam parameters), which leads to higher thermal pollution of the atmosphere. In this case the heat recuperation ratio decreases and at the same time global energy efficiency also decreases down to 60-68 \%.

At the same time increasing the heat recuperation ratio through entire utilization of flue gases sensible heat and also of condensation heat of water vapor from flue gases (implies utilization of heat exchangers with corrosion resistant materials) can increase the global energy efficiency over $95 \%$.

Regarding the annual operation hours of internal combustion engines in cogeneration mode there can be said that the higher the operation hours the more profitable is the cogeneration plant from economic point of view. So, in order to have a more profitable cogeneration plant it should be used for generating and supplying power and heat to technological processes with a long period of operation during entire year.

At the same time, in order to increase global energy efficiency of the company all other technological equipment should be questioned for energy efficiency measures, which can include (Patrascu et al., 2016):

- Operation at full load or close to full load of internal combustion engine, thus leading to maximal efficiency.

- Increasing the annual duration of operation of equipment at nominal parameters.

- Utilization of cogeneration equipment for covering base load energy demands, and for peak load energy demands covering utilization of peak load equipment.

- $\quad$ Keeping optimal temperatures in heat recovery systems of the engine.

- $\quad$ Reducing as much as possible the temperature of exhaust gases evacuated into atmosphere.

- $\quad$ Energy efficiency measures for reducing energy losses in energy transport and distribution systems through thermal insulation.

There are also other measures that can be implemented and can lead to increasing overall energy efficiency:

- Time synchronization of operation of cogeneration plant and technological processes supplied with energy from internal combustion engines.

- Permanent tracking of vital operation parameters of the engine: oil temperature, cooling water flow, pressure in different points, temperatures in heat exchangers.

- $\quad$ Constant monitoring of specific fuel consumption of the engine.

- $\quad$ Periodic check of oil level and its properties.

- $\quad$ Periodic cleaning of engine's radiators. 
- Periodic check of air fans used to cool down engine's room.

- $\quad$ Periodic check of pumping equipment and all pipes.

- Periodic service of the internal combustion engine as specified by engine's manufacturer.

- $\quad$ Periodic check of all monitoring equipment.

- $\quad$ Periodic check of all fittings, pipes and thermal insulation.

PICBE| 213

- Implementation of corrective and preventive maintenance programs.

Other measures that can contribute to increasing energy efficiency:

- Implementation of specific procedures for equipment operation.

- Permanent personnel training with regard to equipment operation and energy efficiency issues.

- Optimization of piping systems in order to reduce redundant pipes as much as possible.

\section{Methodology}

The authors have compared three case studies that aim at implementing cogeneration plant at companies from different industrial sectors. The methodology included the analysis of combined heat and power plants during a certain period of time. There have analyzed the variation of power, heat and global efficiency of all three cogeneration plants. Furthermore there has been studied and compared the advantages of cogeneration compared to separate power and heat generation.

\section{Case studies}

Bellow there are presented three case studies of utilization of internal combustion engines in a cogeneration plant at different industrial companies with different economic profile:

- Cogeneration plant with two internal combustion engines with warm water production only at a company from pharmaceutical sector.

- Cogeneration plant with one internal combustion engine using natural gas with mixed heat recuperation, partial for warm water production using engine's cooling systems and partial for steam generation using heat from flue gases at a beer production company. - Cogeneration plant with one internal combustion engine using natural gas, combined with a superheated steam boiler with supplementary combustion of phenolic products at a company of electrical insulation materials.

\section{Case study 1}

The cogeneration plant installed at a company from pharmaceutical sector includes two internal combustion engines having power rated capacity of $600 \mathrm{~kW}_{\mathrm{e}}$ and heat rated capacity of $740 \mathrm{~kW}$. The heat resulted from engines' operation is collected from both of them through equipment that supply two warm water circuits. The first circuit is preheating supplement water for saturated steam boilers from thermal plant and uses approximately $15 \%$ of total available heat, and the second circuit heats up water for technological purposes during summer time and for heating space purposes during winter time. The operation of equipment is done using a monitoring program aimed at maximizing the useful effect from the points of view power and heat utilization. At the same time there have been regulated both engine for operating in a way to achieve the best efficiency (automation equipment for constant tracking of produced power, increase of preheating 
ratio of air-fuel mixture, increase of heat exchange surface and keeping constant the temperature of engine's cooling agent).

Due to the fact that not all the heat available from engines can be used within technological processes during all months at constant level the global average energy efficiency are variable, as it can be seen figure 1.

Analyzing the results presented in figure 1 there can be said that CHP power efficiency is constant over the analyzed period, reaching at least $95 \%$ from its nominal value. At the same time the CHP heat efficiency varies in a larger domain, between 50 and $85 \%$ of its nominal value.

Consequently, the CHP global efficiency also varies in quite a large domain. This can be explained by the fact that available heat from CHP is not used all the time due to constrains from heat end users.

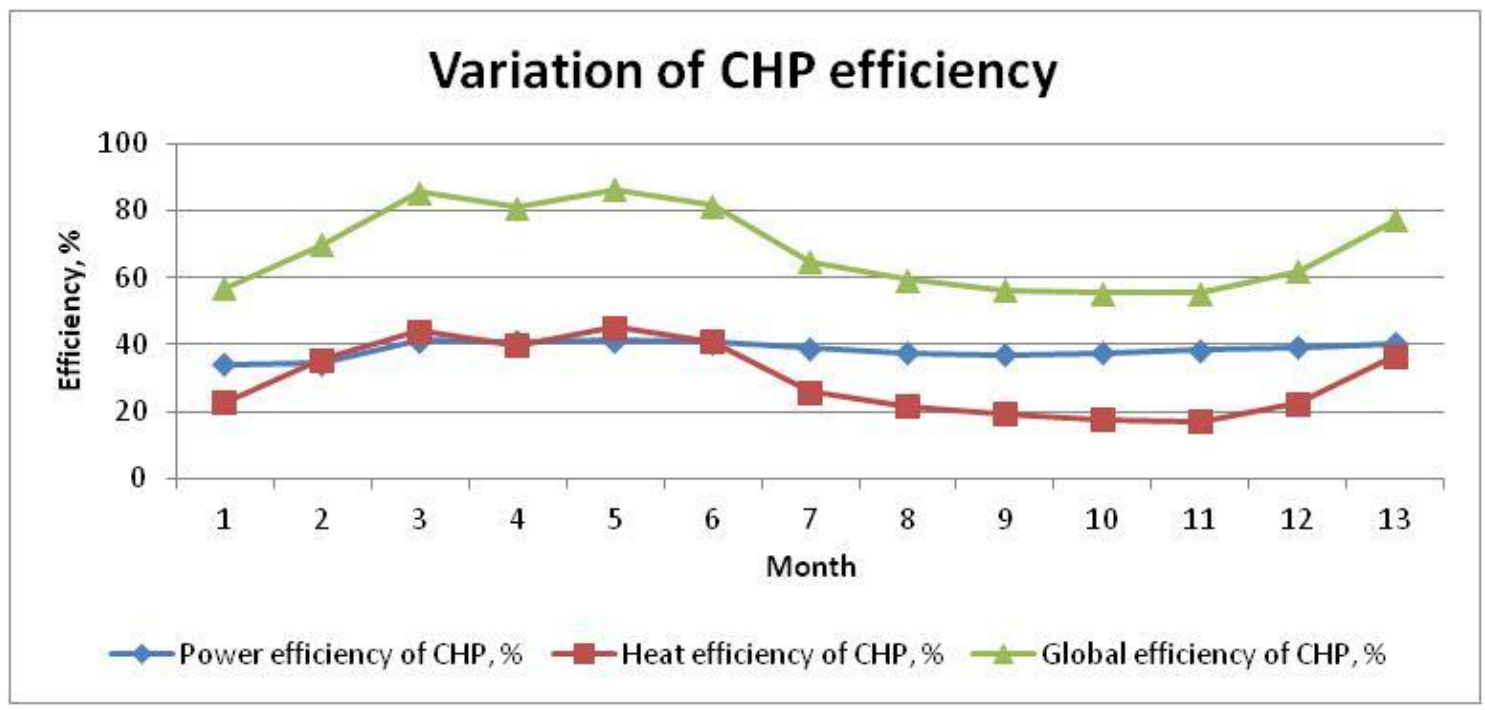

Figure 1. Variation of CHP efficiency for a company from pharmaceutical sector

Source: Authors' own research.

\section{Case study 2}

The cogeneration plant installed at a beer production company include a cogeneration unit based on internal combustion engine using natural gas as primary energy source having power installed capacity of $1 \mathrm{MWe}$ and heat installed capacity of 1.4 MWt. The available heat is recuperated separately from engine's cooling systems for preheating supplement water and returned condensate and from flue gases for saturated steam generation of about 10 bars. The results are presented in figure 2 . Analyzing figure 2 there can be said that, as for the previous case, for this one the global CHP efficiency varies quite a lot and this is due to a large variation of heat CHP efficiency. This is due to the fact that the available heat from internal combustion engine is not used totally all the time. 
The fact the CHP heat and global efficiencies vary in such a large domain led to analyzing the opportunity of installation of a heat storage tank for hot water under pressure. The heat storage tank should be charged during low heat consumption demand period and discharged during high heat consumption demand period.

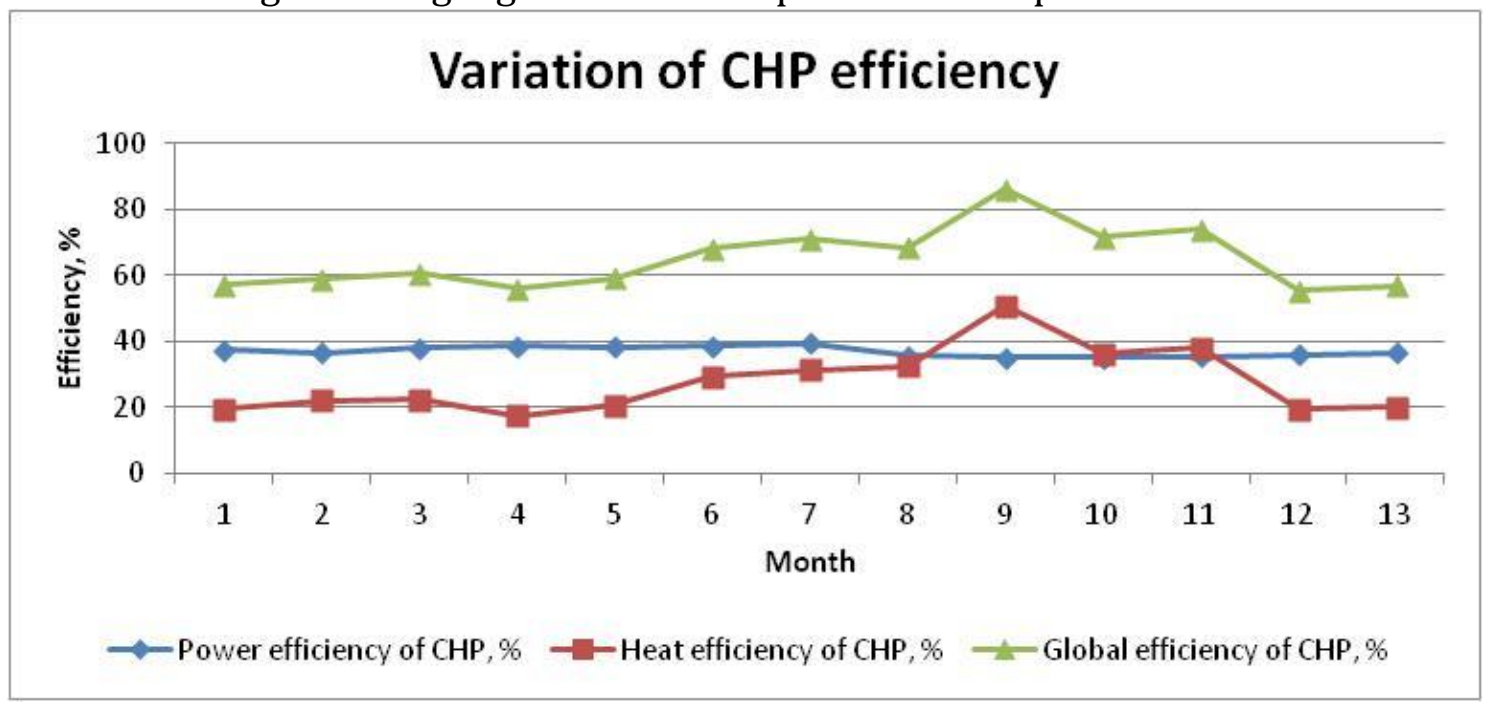

PICBE $\mid 215$

Figure 2. Variation of CHP efficiency for a beer production company

Source: Authors' own research.

\section{Case study 3}

The cogeneration plant has been installed at a company of electrical insulation materials and includes the following main equipment:

- An internal combustion engine having an installed power capacity of $1 \mathrm{MW}_{\mathrm{e}}$.

- $\quad$ A superheated steam boiler (12 bars and $\left.250^{\circ} \mathrm{C}\right)$, equipped with recuperation pipes that allow recovery of heat from flue gases.

- An incineration equipment of secondary technological liquid products, which is included in the steam boiler.

- Two economizers, separately of the boiler, that use available heat from flue gases for preheating water for steam boiler up (between 104 and $180^{\circ} \mathrm{C}$ ).

Recuperation of residual heat from internal combustion engine is made separately producing warm water for preheating supplement water for the boiler and for space heating during winter time, and separately for steam generation from available heat from flue gases. Daily results are presented in figure 3. 


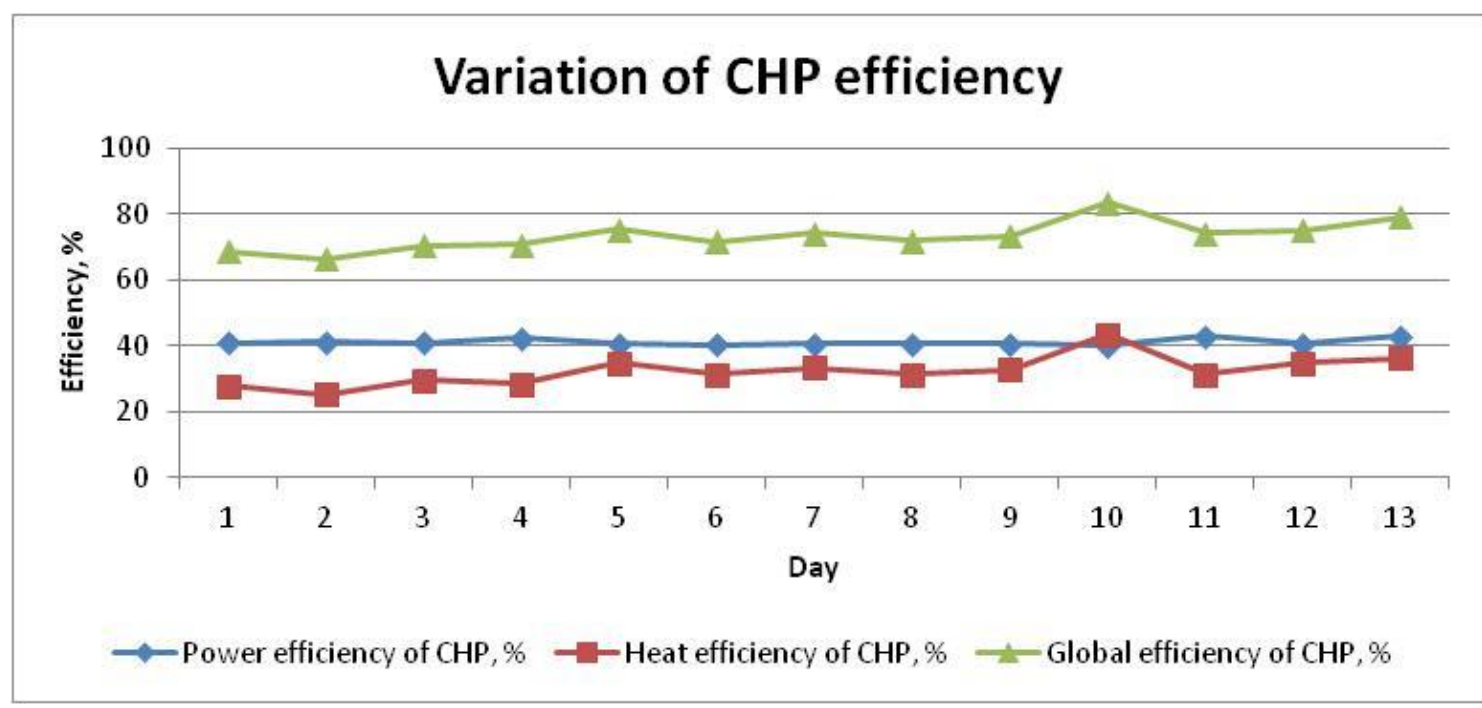

Figure. 3. Variation of CHP efficiency for a company of electrical insulation materials

Source: Authors' own research.

The measurements have been performed on an hourly basis and used for establishing optimal operation regimes.

Analyzing the results there can be said that the operation of CHP plant based on internal combustion engine varies, having periods of operation at full load and periods of operation at partial loads. This can be seen from the graph analyzing the variation of CHP efficiencies.

\section{Conclusions}

Analyzing all three previous presented case studies there can be made the following conclusions about operation of CHP equipment based on internal combustion engines in different industrial companies:

- Implementation of cogeneration solutions based on internal combustion engines lead to significant financial savings through reduction of electricity bill.

- Implementation of cogeneration solutions based on internal combustion engines can also lead to reducing environmental impact through reducing green house gas emissions.

- It ensures higher global energy production efficiency (60-80\%) and higher power efficiency (40-45 \%) compared to National Power System and to separate power and heat generation.

- A CHP plant installed at an industrial company can also lead to increased safety in energy supply of the company.

- A CHP plant installed at an industrial company can also increase the reliability of power supply in cases of National Power Grid faults.

The results of analysis show clearly that the cogeneration technology can lead to different advantages compared to separate energy production. These advantages include increasing energy efficiency, improving economic efficiency of the company and also decreasing the pollutant emissions.

Further on there can be analyzed the efficiency of cogeneration plant operation for different loads, especially for periods when power efficiency/heat decreases. 


\section{References}

Athansovici, V. (2015). Heat Management in Industry, AGIR Press, Bucharest, ISBN 978-973720-597-1, 1340 pages.

Leca, A. and Musatescu, V. (2008). Energy Management, AGIR Press, Bucharest, ISBN 978973-720-190-4, 745 pages.

PICBE $\mid 217$

Pătraşcu, R. and Minciuc, E. (2008). A model for internalization of environmental effects for different cogeneration technologies. Proceedings of the 2nd wseas/iasme international conference on energy planning, energy saving, environmental education, Book Series: Energy and Environmental Engineering Series, Pages: 25-29, Accession Number: WOS:000263153400002, IDS Number: BIV45, ISBN: 978-960-474-016-1.

Pătrașcu, R. and Minciuc, E. (2013a). Cogeneration plant for energy supply of a meat processing company: case study. UPB scientific bulletin, series C, vol. 75, no. 4, ISSN 2286-3540, pp. 269-276.

Pătraşcu, R. and Minciuc, E. (2013b). Energy audit. Examples, Politehnica Press, Bucharest, ISBN 978-606-515-443-8, 113 pages.

Pătrașcu, R., Minciuc, E. and Darie, G. (2013). Case study regarding the energy efficiency of cogeneration compared to separate heat and power supply of a residential area. UPB scientific bulletin, series C, vol. 75, no. 1, ISSN 1454-234x, pp.297-308.

Pătraşcu, R., Minciuc, E. and Darie, G. (2016). Management of secondary energy resources (SER) in industry. 10 $10^{\text {th }}$ International Conference on Business Excellence in Energy, Climate Change and Sustainability, ICBE, Bucharest, Romania.

Pătraşcu, R., Minciuc, E. and Diaconescu, I. (2011). Evaluation of the environmental impact of a cogeneration plant for an urban area. Proceedings of the 7th IASME/WSEAS International Conference on Energy, Environment, Ecosystems and Sustainable Development (EEESD'11), November 17-19, 2011, Angers, France, pp. 118-121, ISSN 978-1-61804-052-7. 